\title{
ANÁLISE HIDROGEOQUIMICA PRELIMINAR DAS FONTES DA REGIÃO DE ÁGUAS DE LINDÓIA
}

\author{
MARIA SZIKSZAY* e JEAN-MARIE TEISSEDRE**
}

\begin{abstract}
In continuation of our work about springs in the São Paulo State, this paper has the finality to analyse, from the chemical and geological point of views, the sources of waters in the region of Águas de Lindóia. A totality of 26 springs has been studied, all belonging to the crystalline complex of metamorphic rocks known under the name of Amparo gneisses.

All of these springs are of feeble discharge with exception of those of the "Balneario de Águas de Lindóia" which are also hypothermal. From the chemical viewpoint, all waters have similar characteristics as much in major elements as in trace elements.

Accordingly to their composition, they can be classified as bicarbonated sodic, calcic and magnesian waters. Some of them is mixed or chloro-sodic.

Only the radioactivity at the spring permits to consider them as mineral waters, having in view their low concentration in dissolved solids.
\end{abstract}

INTRODUÇÃo Em continuação aos nossos estudos sobre os aspectos químicos e geológicos das águas das fontes do Estado de São Paulo, apresentamos os resultados referentes à região de Âguas de Lindóia e arredores.

A finalidade desses estudos e metodologia utilizada foram abordadas no nosso estudo sobre as águas das fontes da borda da Bacia Terciária de São Paulo (Szikszay e Teissedre, 1977).

A área de interesse do estudo cobre cerca de $825 \mathrm{~km}^{2}$, tendo como limites as coordenadas $22^{\circ} 30^{\prime}$ a $22^{\circ} 43^{\prime}$ Lat. S e $46^{\circ} 30^{\prime}$ a $46^{\circ} 46^{\prime}$ Long. W (Fig. 1).

CONTEXTO GEOLÓGICO As fontes da região de Āguas de Lindôia, Lindóia, Sera Negra, Amparo, Monte Alegre do Sul e Socorro, localizam-se nos metamorfitos da região de Amparo, denominados gnaisse Amparo. Este complexo metamórfico é delimitado a leste pelo maciço granítico de Socorro, (Wernick, 1967). O facies gnáissico de Amparo é constituído essencialmente de um biotita-gnaisse com ou sem hornblenda, com intercalações de granada-biotita-xistos, quartzitos, rochas calcossilicatadas e gonditos. Nos eixos anticlinais do gnaisse Amparo ocorrem os facies gnáissicos propriamente dito, situados aproximadamente entre os quartzitos Serra Negra e Boçaina. Segundo Wernick (op. cit.), uma determinação precisa do contato entre os facies migmatítico e gnáissico do gnaisse Amparo é dificultada pela passagem progressiva entre ambos, pela presença de núcleos migmatíticos dentro dos gnaisses, bem como de núcleos de gnaisse dentro dos migmatitos. Ao norte de Serra Negra, na faixa migmatítica, ocorre um pacote gnáissico, que merece ser citado por sua extensão e é denominado de gnaisse Serra Negra. Sua paragênese envolve, essencialmente, plagioclásio ácido, microclínio, quartzo e biotita, com rảas

\footnotetext{
* Instituto de Geociências, Departamento de Geologia Geral da Universidade de São Paulo.

** Instituto de Pesquisas Tecnológicas, Divisão de Mịnas e Geologia Aplicada, São Paulo.
} 
cloritas e apatita. Por sua textura, este gnaisse é bastante semelhante a um granodiorito, como veremos mais adiante. $O$ verdadeiro gnaisse Amparo é representado por uma paragênese variável, mas principalmente a quartzo, plagioclásio, microclínio, biotita, hornblenda, granada, almandina, raras muscovitas e diopsídio. Os migmatitos são constituídos por microclínio, oligoclásio, quartzo e biotita. Conforme a localização, verifica-se uma passagem progressiva dos embrechitos ao facies anatexito.

Afim de correlacionar melhor a composição química das águas das fontes com a litologia, torna-se necessário abordar a geologia de cada fonte separadamente, quando houver mudança de facies numa pequena distância, ou de um grupo, quando se encontram circunscritas à uma pequena área (Fig. 1).

As fontes do balneário de Āguas de Lindóia, Filomena, São Roque, Glória e Beleza, situadas a poucos metros umas das outras, estão localizadas numa faixa de micaxisto de direção $\mathrm{N} 30^{\circ} \mathrm{E} \cdot \mathrm{a} \mathrm{N} 80^{\circ} \mathrm{E}$. Estes micaxistos são cortados por veios de quartzito de 2 a $3 \mathrm{~m}$ de espessura e por uma rocha leucocrática, provavelmente um leptinito, bastante alterado, contendo xenolitos de micaxisto dobrado. As camadas de micaxisto, bem como os veios de quartzito e os contatos com o leptinito mergulham para $70^{\circ} \mathrm{SE}$ a subverticais. Pelo que foi dado observar, parece que as águas destas fontes surgem nos contatos entre os micaxistos e o leptinito ou entre o leptinito e os veios de quartzito. Este comportamento-é visível na fonte Filomena.

Na fonte Lindália, cuja água é explorada através de um poço profundo, não foi possível determinar as litologias atravessadas, porém na superfície se identificou um gnaisse com veios de quartzo em boudinage.

Na fonte Santa Isabel, embora não tenha sido possível conhecer a geologia do ponto de surgência, as rochas aflorantes foram identificadas como um micaxisto contendo lentes de quartzo e cortado por veios de quartzito. Este facies, possuindo uma direção praticamente NS e de mergulho subvertical, é a continuação dos micaxistos identificados mais ao norte do balneário.

Um pouco mais a oeste, encontra-se a fonte São Sebastião surgindo dos gnaisses, através das fraturas, diaclases e xistosidade.

Mais ao sul, no município de Lindóia, foram levantadas as fontes São Benedicto, São José e Santa Bernadette, que pertencem ao facies propriamente dito do gnaisse Amparo. As águas da fonte São Benedicto nascem das fraturas que cortam o biotita-gnaisse. Este é cortado, também, por veios de granito aplítico leucocrático. No sentido da xistosidade, observa-se a presença de nódulo de anfibolito em forma de boudinage. A fonte São José é explorada através de um poço tubular próximo à nascente, cujo perfil geológico é desconhecido.

As outras fontes desta região: Nossa Senhora das Brotas, São Bernardo, São Fransciso e São Jorge, ocorrem no facies migmatítico. Na fonte Nossa Senhora das Brotas foram observados veios de quartzo cortando os gnaisses bastante milonitizados. Na fonte São Jorge ocorre gnaisse com veios de quartzo e anfibolito, bem como na fonte São Francisco no outro lado do muro, enquanto que na fonte São Bernardo a rocha é um migmatito. Na verdade, estamos na faixa de transição entre os dois faceis. Em todas essas fontes as águas brotam das fraturas, diaclases e xistosidade.

A noroeste de Lindóia, pertencendo ao município de Itapira, a fonte Boa Vista se localiza dentro dos gnaisses de direção NS e com mergulho de $70^{\circ} \mathrm{W}$. Observa-se também, perto da nascente, veios de quartzo concordante. A água brota através de fraturas, diaclases e xistosidade. 


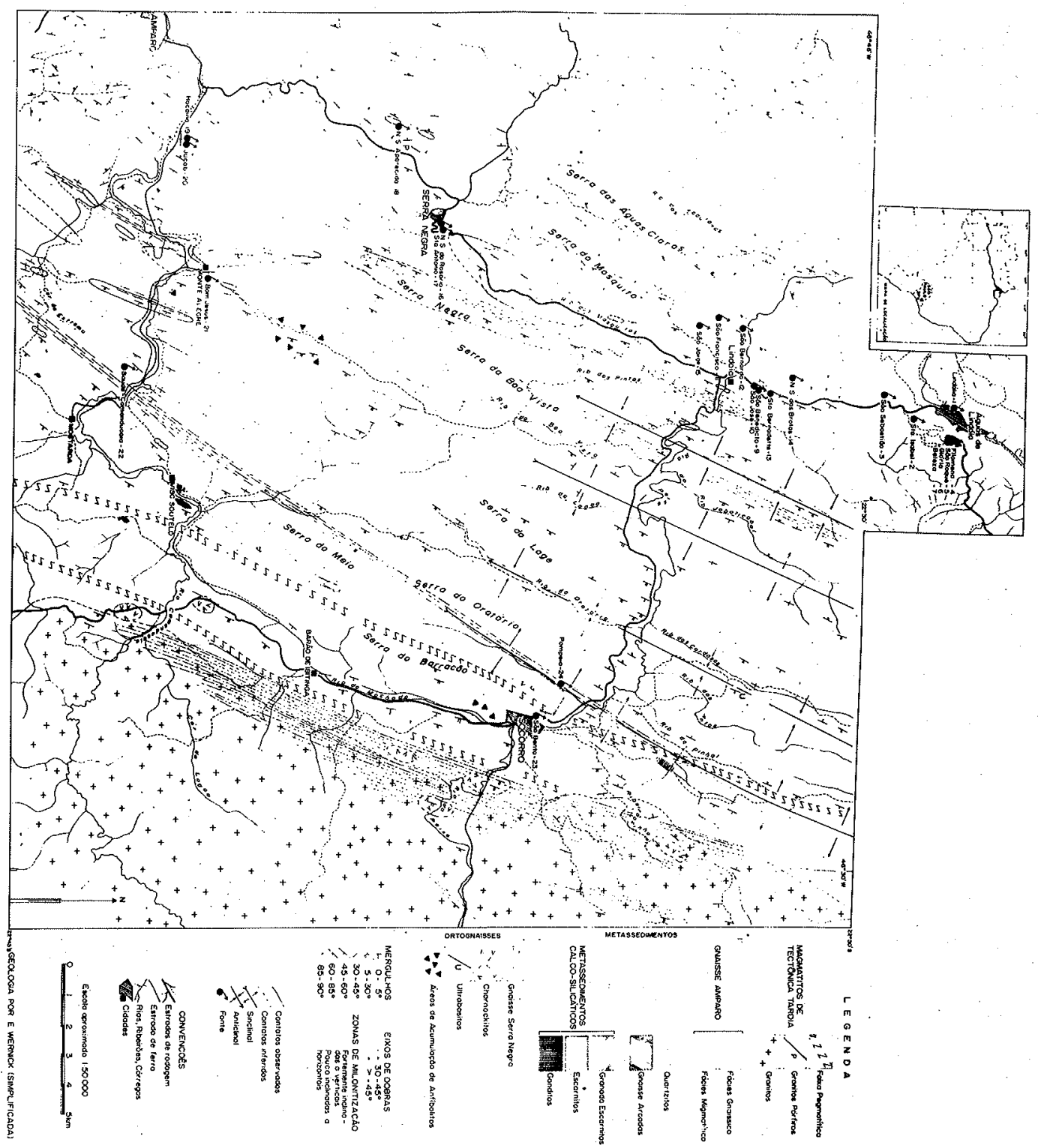

Figura 1 - Mapa geológico e localização das fontes 
Em Serra Negra foram analisadas duas fontes: Nossa Senhora do Rosário e Santo Antonio. Na fonte Nossa Senhora do Rosário afloram rochas melanocráticas com núcleos leucocráticos. A rocha foi identificada como sendo um granodiorito. Segundo Passos Guimarães (1946), os núcleos claros são um granodiorito à biotita, quartzo e andesina e os escuros um granodiorito a hornblenda com oligoclásio, microclínio, quartzo, titanita e zirconita. A nascente se encontra no granodiorito a hornblenda. No centro da cidade, a fonte Santo Antonio nasce num granodiorito milonitizado de cor clara com uma paragênese à quartzo, plagioclásio e epídoto. Dentro do granodiorito, encaixam-se lentes metamorfizadas com estruturas miloní: tica. O gnaisse propriamente dito de Serra Negra, aflorando na entrada da cidade, é cortado por veios de pegmatito e adquire uma textura de migmatito. Por este fato ele pertence aos facies migmatíticos do gnaisse Amparo, segundo Wernick (1967). A forte milonitização perto da fonte Santo Antonio assinala a presença de uma falha $\mathrm{NE}$, o que condicionaria as fontes.

A sudoeste de Serra Negra fica localizada a fonte Nossa Senhora Aparecida, no fundo de um vale. A água sai a partir das fraturas, diaclases e xistosidade dos migmatitos.

Pertencendo ao município de Amparo as fontes Jacob e Bocaina estão situadas nos migmatitos do gnaisse Amparo. Estas rochas são cortadas por veios' de rochas quartzosas aplíticas e apresentam estrutura em forma de boudinage com minerais mesocráticos lhes dando aparência de um anatexito. Isso foi observado principalmente na fonte Jacob, onde a água brota das juntas e xistosidade. No caso da fonte Bocaina, a rocha de cor leucocrática é muito silicatada e deve constituir um veio mais claro dentro dos migmatitos.

Em Monte Alegre do Sul somente foram analisadas as fontes Bom Jesus e da Saúde. A fonte Bom Jesus nasce numa rocha identificada como gnaisse à textura embrechítica, de díreção quase NS, bem evidenciada pelas camadas escuras de biotita e os veios de quartzo. A fonte da Saúde nasce de uma rocha bastante fissurada, parecendo um granito gnaisse à tendência embrechítica, de direção $\mathrm{N} 60^{\circ} \mathrm{E}$ e com mergulho de $70^{\circ} \mathrm{E}$. Essas duas fontes fazem parte do facies gnáissico e as águas emergem das fraturas, diaclases e xistosidade.

No município de Socorro foram visitadas as fontes São Bento e Pompéia. A primeira se encontra num gnaisse rosado de direção $\mathrm{N} 30^{\circ} \mathrm{E}$ e com mergulho subvertical. A fonte Pompéia nasce no contato de um pegmatito de quartzo róseo com fenocritais de feldspato de $5 \mathrm{~cm}$ de aresta. O gnaisse pertence ao facies gnáissico com direção de $\mathrm{N} 45^{\circ} \mathrm{E}$.

Pertencendo ao município de Valinhos, apenas as fontes Sônia e Santa Tereza foram analisadas. A rocha da qual surge a fonte Sônia foi identificada como um granodiorito cortado por veios pegmatíticos com feldspato, biotita, turmalina e piroxênio. Na fonte Santa Tereza não existe nenhum afloramento perto da nascente, tornando-se portanto difícil de precisar sua geologia.

Observe-se um alinhamento das fontes na direção NE desde Águas de Lindóia até Bocaina. Uma zona de cataclase (verificada nas emergências de certas fontes) sugere uma falha como sendo responsável pelo termalismo de certas fontes.

$\mathrm{Na}$ Tab. I sintetizamos as principais características das fontes.

RESULTADOS E INTERPRETAÇÃO ASPECTOS FÍSICOS Os resultados
das medidas físicas encontram-se na Tab. II.


Tabela I - Características hidrogeológicas das fontes

\begin{tabular}{|c|c|c|}
\hline FONTE & LITOLOGIA & FORMA DE OCORRÊNCIA \\
\hline Lindália & gnaisse? & poço tubular \\
\hline Santa Isabel & micaxisto e quartzito & fraturas e diaclases \\
\hline São Sebastião & gnaisse & fraturas e diaclases \\
\hline Filomena & leptinito, micaxisto e quartzito & contato leptinito-quartzito \\
\hline São Roque & leptinito, micaxisto e quartzito & contato leptinito-micaxisto \\
\hline Glória & leptinito, micaxisto e quartzito & contato leptinito-micaxisto \\
\hline Beleza & leptinito, micaxisto e quartzito & contato leptinito-micaxisto \\
\hline Boa Vista & gnaisse & $\begin{array}{l}\text { fraturas e diaclases na xistosi- } \\
\text { dade }\end{array}$ \\
\hline São.Benedicto & biotita-gnaisse & fraturas \\
\hline São José & gnaisse? & poço tubular \\
\hline São Francisco & gnaisse, migmatito & fratura e diaclases \\
\hline São Bernardo & migmatito & fratura \\
\hline Santa Bernadette & gnaisse & $\begin{array}{l}\text { fraturas, diaclases e xistosi- } \\
\text { dade }\end{array}$ \\
\hline Nossa Sra. das Brotas & migmatito e veios de quartzo & fraturas e xistosidade \\
\hline Șão Jorge & $\begin{array}{l}\text { migmatito com veios de quartzo } \\
\text { e anfibolito }\end{array}$ & $\begin{array}{l}\text { fraturas, diaclases e xistosi- } \\
\text { dade }\end{array}$ \\
\hline Nossa Sra. do Rosário & granodiorito & fraturas \\
\hline Santo Antonio & granodiorito milonitizado & fraturas \\
\hline Nossa Sra. Aparecida & migmatito & $\begin{array}{l}\text { fraturas, diaclases e xistosi- } \\
\text { dade }\end{array}$ \\
\hline Bocaina & migmatito & diaclases e xistosidade \\
\hline Jacob & migmatito-anatexito & diaclases e xistosidade \\
\hline Bom Jesus & gnaisse-embrechito & $\begin{array}{l}\text { fraturas, diaclases e xistosi- } \\
\text { dade }\end{array}$ \\
\hline da Saúde & granito-gnaisse-embrechito & $\begin{array}{l}\text { fraturas, diaclases e xistosi- } \\
\text { dade }\end{array}$ \\
\hline São Bento & gnaisse & fraturas \\
\hline Pompéia & gnaisse e pegmatito & $\begin{array}{l}\text { contato veio de quartzo e } \\
\text { gnaisse }\end{array}$ \\
\hline Sônia & granodiorito & fraturas e diaclases \\
\hline Santa Tereza & $?$ & $?$ \\
\hline
\end{tabular}


Tabela II - Parâmetros físicos das águas

\begin{tabular}{|c|c|c|c|c|c|c|}
\hline Local & $\begin{array}{l}\text { Nome da } \\
\text { Fonte }\end{array}$ & $\begin{array}{c}\mathrm{T} d \mathrm{da} \\
\text { agua }\end{array}$ & $\mathrm{pH}$ & $\begin{array}{l}\text { Condutiv. } \\
\mu \mathrm{mho} / \mathrm{cm}\end{array}$ & $\begin{array}{c}\text { Radiotiv. } \\
\text { nCil/1 }\end{array}$ & $\begin{array}{c}\text { Vazão } \\
1 / \mathrm{s}\end{array}$ \\
\hline Águas de Lindóia & Lindália & 22 & 5,3 & 185 & $\begin{array}{l}11,51^{+} \\
14,65^{++}\end{array}$ & 3,88 \\
\hline Äguas de Lindóia & Santa Isabel & 21,5 & 5,3 & 80 & $1,96^{+}$ & 1,67 \\
\hline Águas de Lindóia & São Sebastião & 22,5 & 5,5 & 176 & $1,88^{+}$ & 2,08 \\
\hline Āguas de Lindóia & Filomena & 27 & 5,7 & 132 & $0,73^{++}$ & 3,33 \\
\hline Āguas de Lindóia & São Roque & 28 & 5,3 & 115 & $\begin{array}{l}1,31^{+} \\
0,91^{++}\end{array}$ & 7,78 \\
\hline Águas de Lindóia & Glória & 26,5 & 5,3 & 84 & & \\
\hline Águas de Lindóia & Beleza & 28 & 5,5 & 120 & $5,34^{+}$ & \\
\hline Itapira & Boa Vista & 21,5 & 5,7 & 280 & $1,40^{++}$ & 0,58 \\
\hline Lindóia & São Benedicto & 21 & 5,3 & 80 & $5,94^{+}$ & 0,25 \\
\hline Lindóia & São José & 23 & 5,3 & 110 & $2,96^{+}$ & 3,33 \\
\hline Lindóia & São Francisco & 22 & 5,3 & 95 & $1,92^{+}$ & 1,10 \\
\hline Lindóia & São Bernardo & 22 & 5,3 & 120 & $2,04^{+}$ & 1,05 \\
\hline Lindóia & Sta. Bernadette & 21 & 5,3 & 90 & $2,00^{+}$ & 0,73 \\
\hline Lindóia & N. Sra. das Brotas & 21,5 & 5,3 & 85 & $6,21^{+}$ & 1,67 \\
\hline Lindóia & São Jorge & 22 & 5,3 & 70 & $2,62^{+}$ & 1,00 \\
\hline Serra Negra & N. Sra. do Rosário & 20 & 4,7 & 80 & $\begin{array}{l}4,72^{+} \\
0,134^{+++}\end{array}$ & 0,22 \\
\hline Serra Negra & Santo Antonio & 19 & 4,7 & 120 & $1,65^{+++}$ & 0,12 \\
\hline Serra Negra & N. Sra. Aparecida & 20,5 & 4,7 & 56 & $\begin{array}{l}2,03^{+} \\
1,06^{+++}\end{array}$ & 1,42 \\
\hline Amparo & Bocaina & 20 & 4,7 & 125 & $\begin{array}{l}2,41^{+} \\
0,952^{+++}\end{array}$ & 0,12 \\
\hline Amparo & Jacob & 22 & 4,7 & 112 & $1,13^{+++}$ & 0,40 \\
\hline Monte Alegre do Sul & Bom Jesus & 20 & 4,7 & 90 & $1,92^{+++}$ & 0,12 \\
\hline Monte Alegre do Sul & da Saúde & 20,5 & 4,7 & 40 & $\begin{array}{l}\mathbf{5}, 67^{+} \\
\mathbf{0}, 36^{+++} \\
\end{array}$ & 1,67 \\
\hline Socorro & São Bento & 19,5 & 4,7 & 75 & $\begin{array}{l}1,88^{+} \\
0,12^{+++} \\
\end{array}$ & 0,13 \\
\hline Socorro & Pompéia & 20,5 & 4,7 & 120 & $\begin{array}{l}3,2^{+} \\
0,44^{++}\end{array}$ & 1,10 \\
\hline Valinhos & Sônia & 21,5 & 4,7 & 110 & $4,00^{++}$ & \\
\hline Valinhos & Santa Tereza & 21,5 & 4,7 & 130 & & 0,50 \\
\hline
\end{tabular}

Obs.: Dados de radioatividade $-\quad+$ Longo (1967) 
Temperatura A temperatura das águas, na grande maioria, caracteriza fontes frias, salvo as fontes Filomena, São Roque, Glória e Beleza $\left(27^{\circ}, 28^{\circ}, 26,5^{\circ}\right.$ e $28^{\circ} \mathrm{C}$, respectivamente) do balneário de Águas de Lindóia. Conforme o nosso Código de Águas, estas fontes podem ser classificadas como fontes hipotermais. A razão mais prövável da temperatura elevada pode ser o gradiente geotérmico. É impossível identificar os grifões porque o balneário é construído sobre eles. Outro fato é que as camadas possuem um mergulho de $70^{\circ}$ a subvertical, o que implica numa rápida circulação ascendente das águas no contato dos veios de quartzito com o leptinito e os micaxistos. A temperatura do restante das águas varia entre $19^{\circ}$ a $23^{\circ} \mathrm{C}$, muitas vezes coincidindo com a temperatura do ar, refletindo assim uma circulação pouco profunda.

$p H \quad$ Identificam-se dois grupos de águas quanto ao $\mathrm{pH}$. Um com $\mathrm{pH}$ variando de 5,3 a 5,7, englobando as águas da região de Águas de Lindóia e Lindóia, e outro com $\mathrm{pH}=4,7$ referente às águas da região de Serra Negra, Amparo, Monte Alegre do Sul, Socorro e Valinhos. Essa diferença é significativa, pois todas as fontes estão localizadas em rochas cristalinas ácidas apresentando uma paragênese bem semelhante.

Condutividade A condutividade das águas varia de 40 a $280 \mu \mathrm{mho} / \mathrm{cm}$, refletindo, portanto, mineralização variada, porém não muito elevada. Os valores indicam as condições de circulação. Em geral, o tempo de percolação é curto, fato que não permite uma dissolução e acumulação maior dos sais.

Radioatividade Os dados de radioatividade foram extraídos de Longo (1967), alguns mais antigos de Souza Lopes (1956) e outros bem recentes, Oliveira (comunicação pessoal).

Sabe-se que a maioria das rochas cristalinas são radioativas. Especialmente os granitos e rochas semelhantes são mais ricas em rádio, tório e urânio (Castany, 1967). Portanto, certa radioatividade pode ser esperada nas águas das rochas cristalinas.

De acordo com o Código de Minas do Brasil, as águas das fontes ora estudadas pertencem a duas classes distintas:

- radioativas: Fontes Lindália, Beleza, São Benedicto, Nossa Senhora das Brotas, Nossa Senhora do Rosário e da Saúde;

- fracamente radioativas: as restantes. Sobre as águas das fontes Glória e Santa Tereza não existem dados.

Segundo Oliveira (comunicação pessoal), a radioatividade das águas das fontes Nossa Senhora do Rosário, Bocaina, da Saúde, São Bento e Pompéia é devida a uma pequena. quantidade de rádio e de radônio desprezivel, enquanto que as das fontes Santo Antonio, Nossa Senhora Aparecida, Jacob e Bom Jesus aparesentam pequena quantidade de rádio e grande teor de radônio.

Vazão As vazões das fontes estudadas variam de 0,12 a 7,78 1/s. Observa-se que as fontes da região de Águas de Lindóia possuem uma vazão bem superior às demais. Este comportamento parece associado à pluviometria, cuja média anual da região de Águas de Lindóia atinge $1600 \mathrm{~mm}$ contra $1400 \mathrm{~mm}$ no restante da região. As precipitações são favorecidas pela barreira natural da Serra dos Coutos a oeste. 
As vazões relativamente mais altas, registradas nas fontes do Balneário de Águas de Lindóia, são ainda devidas à presença de um contexto hidrogeológico especialmente favorável. Com efeito, os aspectos estruturais propiciam aberturas, cujas zonas de recargas se encontram em cotas topográficas elevadas gerando importantes cargas hidráulicas. As estruturas são subverticais, favorecendo a circulação profunda, conforme atestam as temperaturas anotadas. As surgências, localizam-se nos contatos litológicos no fundo do vale.

AȘPECTOS QUÍMICOS Resultados das análises Na Tab. III apresentamos os parâmetros químicos referentes aos elementos maiores.

Estes dados indicam que os sólidos totais dissolvidos variam de 38 a $220 \mathrm{mg} / \mathrm{l}$. Não é possivel identificar nenhuma separação regional ou por litologia no que se refere à concentração total em sais. A freqüência de valores situados entre $60 \mathrm{e}$ $80 \mathrm{mg} / \mathrm{l}$ atinge $38 \%$ e de 80 a $100 \mathrm{mg} / 1,26 \%$. As demais concentrações encontramse em percentagens menores.

As concentrações em oxigênio variam de 5 a $21 \mathrm{mg} / \mathrm{l}$. Os menores valores pertencem às fontes da região de Amparo.

Todas as águas apresentam concentrações bastante elevadas em $\mathrm{CO}_{2}$ e $\mathrm{HCO}_{3}^{-}$, indicando a grande atividade bioquímica no solo atravessado pelas águas de infiltração de origem meteórica.

A presença dos componentes do ciclo do nitrogênio $\left(\mathrm{NH}_{4}^{-} \mathrm{NO}_{2}^{-} \mathrm{NO}_{3}^{-}\right)$vem corroborar a existência de intensa atividade bioquímica nos domínios de recarga das fontes. Apesar de os teores serem baixos, seria aconselhável o desenvolvimento de pesquisas com vistas a caracterização de suas origens.

Os elementos maiores restantes (cátions e ânions) não mostram grande diferenciação nas águas; refletindo condições hidrogeológicas relativamente homogêneas. Uma exceção pode ser feita para o cálcio nas fontes São Sebastião, São Roque, Boa Vista, São José, magnésio nas de Filomena, Beleza, Boa Vista e sódio na Lindália, Nossa Senhora do Rosário, Santo Antonio e Bocaina. Nas proximidades da fonte Boa Vista foi verificada a mineração de calcário dolomítico; que pode ser responsável pelo teor mais elevado em cálcio e magnésio nessas águas.

Quanto aos elementos traços, observa-se uma diferenciação em termos de brometo e iodeto. Estes dois elementos faltam nas águas das fontes de Águas de Lindóia e algumas de Lindóia. A presença de brometo e iodeto nas águas de certas fontes pa-" rece estar ligada a situação geológica destas. De fato, as rochas encontradas revelam uma forte milonitização com um remanejamento estrutural indicadores de falhas.

O flúor está presente em todas as águas, porém as maiores concentrações pertencem às águas das fontes Santa Isabel, São Sebastião, Beleza, Boa Vista, Nossa Senhora do Rosário, Nosșa Senhora Aparecida, Bocaina e Bom Jesus. Ao fluoreto é atribuído uma origem juvenil, a partir de processos metamórficos, de acordo com Castany (1967). O comportamento dos demais parâmetros físicos e químicos não possibilita, entretanto, confirmar tal hipótese.

As maiores concentrações de boro pertencem às águas das fontes Beleza, São Benedicto, São Bernardo, Nossa Senhora das Brotas, Nossa Senhora Aparecida, Bocaina, Bom Jesus, da Saúde e Pompéia. No caso da fonte Beleza, sua presença poderia estar relacionada a uma contribuição magmática. Nas restantes predomina a influência da litologia. 
Tabela III - Resultados das análises - Elementos maiores (mg/l)

\begin{tabular}{|c|c|c|c|c|c|c|c|c|c|c|c|c|c|c|c|c|c|c|c|}
\hline Local & $\begin{array}{l}\text { Nome da } \\
\text { Fonte }\end{array}$ & $\begin{array}{l}\text { Data da } \\
\text { andilise }\end{array}$ & $\begin{array}{l}\text { Sólidos } \\
\text { totais } \\
\text { dissolv. }\end{array}$ & oy & $\mathrm{CO}_{2}$ & $\mathrm{Ca}$ & $\mathrm{Mg}$ & $\mathrm{Na}$ & K & $\mathrm{Al}$ & $\mathrm{Fe}$ & $\mathrm{SiO}_{2}$ & $\mathrm{HCO}_{3}$ & $\mathrm{Cl}$ & $\mathrm{SO}_{4}$ & $\mathrm{PO}_{4}$ & $\mathrm{~N}_{4}$ & $\mathrm{NO}_{2}$ & $\mathrm{NO}_{3}$ \\
\hline Águas de Lindóia & Lindália & $5: 02: 76$ & 160 & 14 & 100 & 8 & 10 & 12 & 5 & 0 & 0 & 5.5 & 70 & 10 & I & 0.1 & 0.1 & 0.05 & 9.2 \\
\hline Agguas de Lindóia & Santa Isabel & 6.02 .76 & $74^{\circ}$ & 21 & 48 & 3 & 7 & 1.6 & 1.5 & 0.01 & 0 & 5.5 & 50 & 3 & 2 & 0.03 & 0.02 & 0.05 & 1.6 \\
\hline Águas de Lindóia & São Sebastiẫo & $6: 02: 76$ & 150. & 20 & 40 & 23.5 & 9.2 & 0.6 & 1.6 & 8 & 0.01 & 4.6 & 100 & 5 & 3 & 0.17 & 0.1 & 0.03 & 7.9 \\
\hline Äguas de Lindóia & Filomena & $7 ; 02: 76$ & 110 & 20 & 32 & 6 & 16 & 6.4 & & 0 & 0 & 6.5 & 70 & 10 & 0 & 0.14 & 0.5 & 0.03 & 9.6 \\
\hline Äguas de Lindöia & São Roquẹ & $7 / 02 / 76$ & 86 & 20 & 16 & 11.4 & 2.9 & 1,8 & 2.1 & 0 & 0 & 5.5 & 55 & 3.5 & 2 & 0.05 & 0.14 & 0.04 & 3.4 \\
\hline Åguas de Lindóia & Glôtria & $7.02 / 76$ & 68 & 21 & 28 & 4 & 10 & 3.2 & & 0 & 0 & 5.4 & 50 & 5 & 0.4 & 0.06 & 0.2 & 0.05 & 6.6 \\
\hline Águas de Lindóia & Beleza & $7 / 02 / 76$ & 100 & 20 & 56 & 9 & 12 & 6.4 & & 0 & 0 & 5 & 60 & 10 & 3 & 0.1 & 0.15 & 0.03 & 8.8 \\
\hline Irapira & Boa Vista & $6 / 02 / 76$ & 220 & 19 & 40 & 24,2 & 23.9 & 8.2 & 3.4 & 0.001 & 0.01 & 4.2 & 170 & 5 & 0 & 0.64 & 0.11 & 0.03 & 9,2 \\
\hline Lindóia & Sāo Benedicto & $26 / 03 / 76$ & 74 & 12 & 80 & 7.8 & 1.9 & 9.0 & 1.8 & 0.008 & 0 & 6,2 & 50 & 1.7 & 0 & 0.25 & 0.45 & 0.06 & 9.6 \\
\hline Lindōia & São josée & $26 / 03 / 76$ & 100 & 7 & 64 & 17.1. & 3.7 & 2.7 & 2.5 & 0.012 & 0.01 & 6.2 & 62.6 & 4,2 & 4 & 0.23 & 0.15 & 0.05 & 4.0 \\
\hline Lindóia & Sâo Francisco & $27 / 03 / 76$ & 84 & 9 & 88 & 6.0 & 8.0 & 6.0 & & 0 & 0.04 & 6.4 & 48 & 8 & 2 & 0.06 & 0 & 0.06 & 9.2 \\
\hline Lindóia & São Bernardo & $27 / 03 / 76$ & 105 & 11 & 16 & 8.7 & 3.7 & 8.1 & 11.5 & 0.03 & 0 & 6.2 & 46 & 10 & 0 & 0.15 & 0 . & 0.06 & 9.2 \\
\hline Lindöia & Santa Bernadetce & $27 / 03 / 76$ & 82 & 9 & 60 & 4.0 & 8.6 & 5.9 & 2.4 & 0 & 0 & 6.0 & 50 & 5 & 0 & 0.24 & 0 & 0.05 & 8.8 \\
\hline L.indóia & Nossa Sra. das Brotas & $27 / 03 / 76$ & 78 & 8 & 100 & 4.1 & 5.7 & 7.5 & 2.5 & 0.025 & 0.02 & 7.0 & 40 & 2.5 & 0 & 0.2 & 0 & 0.03 & 9.6 \\
\hline Lindóia & Sâo Jorge & $28 / 03 / 76$ & 62 & 15 & 100 & 2.2 & 3.6 & $\neq .0$ & 4.5 & 0 & 0 & 5.5 & 20 & 7 & 0 & 0.08 & 0 & 0.05 & .11 .0 \\
\hline Serra Negra & Nassa Sra. do Rosário & $9: 09 ; 76$ & 76 & 9 & 12 & 1.2 & 3,9 & 14.1 & 1.0 & 0.005 & 0.04 . & 7.5 & 35 & 7.5 & 0 & 0.17 & 0.1 & 0.05 & 13.6 \\
\hline Serra Negra & Santo Antonio & $9 / 09 ; 76$ & 110 & g & 80 & 7.0 & 4.0 & 11.2 & 1.5 & 0 & 0 & 8.0 & 6.5 & 7.5 & o & 0.05 & 0 & 0.08 & 5.6 \\
\hline Serra Negra & Nossa Sra. Apareciila & $11: 09 / 76$ & 42 & 8 & 32 & 1.2 & 1.6 & 3.3 & 1.39 & 0.001 & 0.001 & 4.3 & 17 & 3.0 & 0 & 0.1 & 0 & 0.06 & 12.1 \\
\hline Amparo & Bocaina & $10.09: 76$ & 110 & 5 & 12 & 10.0 & 2.9 & 15.5 & 1.52 & 0 & 0.02 & 6.8 & 70 & 10.0 & 0 . & 0.15 & 0 & 0.07 & 10.1 \\
\hline Amparo & Jacob & 10/09/76 & 98 & 5 & 32 & 6.2 & 3.15 & 9.3 & 2.3 & 0 . & 0.01 & 7.0 & 50 & 5,0 & 0 & 0.05 & 0 & 0.06 & 1.32 \\
\hline Monte Alggre do Sul & Bom Jessus & $10: 09 / 76$ & 84 & 9 & 28 & 5.4 & 1.74 & 4.9 & 2.6 & 0 & 0.01 & 6.0 & 30 & 5.0 & 0 & 0.12 & 0 & 0.07 & 10.3 \\
\hline Monic Alggre do Sul & da Saúcle & $10: 09,76$ & 38 & 9 & 20 & 1.6 & 1.20 & 2.5 & 2.4 & 0 & 0 & 5.0 & 10 & 5.5 & 3 & 0 & 0 & 0.06 & 1.7 \\
\hline Secorro & Sầo Bento & 11.09 .76 & 68 & 9 & 20 & 2.7 & 1.08 & 6.9 & 2.27 & 0 & 0.01 & 4.6 & 20 & 5,0 & 0 & 0.02 & 0 & 0.06 & 6.7 \\
\hline Socorro & Pompria & 11.0976 & 80 & 9 & 24 & 5.8 & 2.8 & 6.9 & 1.97 & 0 & 0.01 & 4.9 & 40 & 7.5 & 1 & 0.11 & 0 & 0.06 & 7.2 \\
\hline Valinhos & Sónia & 1.10.76 & 70 & 9 & 40) & 1.8 & 1.3 & 8.2 & 2.9 & 0.001 & 0.01 & 5.5 & 20 & 5.0 & 1 & 0.15 & 0 . & 0.06 & $12.7^{\circ}$ \\
\hline Valinhos & Santa Tereza & 11076 & 80 & 8 & 28 & 3.9 & 3.5 & 7.8 & 3.03 & 0.04 & 0.01 & 6.2 & 40. & 5.0 & 1 & 0.18 & $0^{\circ}$ & 0.07 & 7.2 \\
\hline
\end{tabular}

Analisadas por: Maria Sziksxay 
Tabela IV - Resultados das análises - Elementros traços (mg/l)

\begin{tabular}{|c|c|c|c|c|c|c|c|c|c|c|}
\hline Local & Nome da Fonte & I & $\mathrm{Br}$ & $\mathbf{F}$ & B & $\mathbf{N i}$ & $\mathrm{Cu}$ & $\mathrm{Cr}$ & $\mathrm{Zn}$ & $\mathrm{Pb}$ \\
\hline Âguas de Lindóia & Lindália & 0 & 0 & 1,0 & 0,4 & 0 & 0,02 & 0,018 & 0,1 & 0,1 \\
\hline Águas de Lindóia & Santa Isabel & 0 & 0 & 1,05 & 0,9 & 0,01 & 0,01 & 0,018 & 0,09 & 0,11 \\
\hline Águas de Lindóia & São Sebastião & 0 & 0 & 1,04 & 0,8 & 0 & 0,02 & 0,018 & 0,1 & 0,14 \\
\hline Águas de Lindóia & Filomena & 0 & 0. & 1,0 & 0,4 & 0,02 & 0 & 0,018 & 0,07 & 0,12 \\
\hline Ãguass de Lindóia & São Roque & 0 & 0 & 1,0 & 0,7 & 0,02 & 0,03 & 0,017 & 0,08 & 0,062 \\
\hline Águas de Lindóia & Glória & 0 & 0 & 0.95 & 0,4 & 0,05 & 0 & 0,02 & 0,08 & 0,06 \\
\hline Águas de Lindóia & Beleza & 0 & 0 & 1,02 & 1,5 & 0,02 & 0,02 & 0.12 & 0,08 & 0,11 \\
\hline Itapira & Boa Vista & 0,018 & 0 & 1,04 & 0,3 & 0,03 & 0,01 & 0,02 & 0,07 & 0,095 \\
\hline Lindóia & Sāo Benedicto & 0 & 0 & 1,01 & 1,2 & 0 & 0 & 0,03 & 0,1 & 0,065 \\
\hline Lindóia & São José & 0 & 0,08 & 1,01 & 0,9 & 0,03 & 0,07 & 0,022 & 0,2 & 0,14 \\
\hline Lindóia & São Francisco & 0 & 0 & 0,95 & 0,9 & 0,06 & 0,02 & 0,018 & 0,09 & 0,075 \\
\hline Lindóia & São Bernardo & 0 & 0 & 0,96 & 1,4 & 0,03 & 0,04 & 0,01 & 0,08 & 0,15 \\
\hline Lindóia & Santa Bernadette & 0 & 0 & 0,98 & $0,5^{\circ}$ & 0,02 & 0,03 & 0,012 & 0,1 & 0,078 \\
\hline Lindôia & Nossa Sra. das Brotas & 0 & 0 & 0,98 & 1,3 & 0 & 0,02 & 0,019 & 0,09 & 0,028 \\
\hline Lindóia & São Jorge & 0,1 & 0,01 & 0,95 & 0,7 & 0 & 0,04 & 0,018 & 0,1 & 0,08 \\
\hline Serra Negra & Nossa Sra. do Rosário & 0 & 0 & 1,1 & 0,9 & 0,1 & 0,04 & 0,02 & 0,1 & 0,046 \\
\hline Serra Negra & Santo Antonio. & 0,04 & 0.01 & 0,92 & 0,5 & 0 & 0,04 & 0,022 & 0,09 & 0,03 \\
\hline Serra Negra & Nossa Sra. Aparecida & 0,01 & 0,01 & 1,02 & 1,2 & 0,01 & 0,03 & 0,02 & 0,07 & 0,04 \\
\hline Amparo & Bocaina & 0.01 & 0,019 & 1,05 & 1,2 & 0 & 0,02 & 0,018 & 0,09 & 0,028 \\
\hline Amparo & Jacob & 0 & 0 & 1,0 & 0 & 0.03 & 0 & 0,02 & 0,08 & 0,042 \\
\hline Monte Alegre do Sul & Bom Jesus & 0,08 & 0 & 1,04 & 1,1 & 0 & 0,04 & 0,02 & 0,09 & 0,031 \\
\hline Monte Alegre' do Sul & da Saúde & 0,08 & 0,02 & 1,0 & 1,2 & 0,03 & 0.04 & 0,30 & 0,08 & 0.03 \\
\hline Socorro & São Bento & 0 & 0,018 & 1,0 & 0,8 & 0 & 0,02 & 0,02 & 0,1 & 0,02 \\
\hline Socorro & Pompéia & 0 & 0 & 0,95 & 1,4 & 0,02 & 0,03 & 0,018 & 0,9 & 0,045 \\
\hline Valinhos & Sônia & 0 & 0 & 0,96 & 0,9 & $0 ; 02$ & 0,03 & 0,010 & 0,08 & 0,034 \\
\hline Valinhos & Santa Tereza & 0 & 0 & 1,0 & 0,9 & 0,01 & 0,01 & 0,012 & 0,9 & 0,11 \\
\hline
\end{tabular}


O níquel é um elemento que se encontra associado com minerais tais como hornblenda e biotita. Os teores mais elevados ocorrem nas águas das fontes Glória, São Francisco e Nossa Senhora do Rosário. Esta última surgindo de granodioritos com hornblenda apresenta, em conseqüência, concentração especialmente elevada.

$\mathrm{O}$ cobre está associado à presença de hornblenda, biotita, anortita e oligoclásio. Encontra-se, com efeito, em teores menos elevados nas águas das fontes situadas no facies gnáissico, que segundo Wernick (1967) é um biotita-gnaisse.

$\mathrm{O}$ cromo encontra-se em teores mais ou menos iguais em todas as águas, excetuando a fonte da Saúde onde sua presença pode ser devida a granada, no qual o cromo figura como acessório.

O zinco é mais abundante nas águas das fontes São José, da Saúde e Santa Tereza. O zinco acompanha os minerais hornblenda, olivina, augita, biotita e magnetita. Encontra-se, com efeito, em teores especialmente elevados, nas águas das fontes São José e da Saúde, que emergem no domínio do facies biotita-gnáissico.

O chumbo encontra-se em teores mais elevados nas águas da região de Águas de Lindóia e Lindóia, especialmente nas fontes São Sebastião, São José e São Bernardo.

INFLUÊNCIA DA LITOLOGIA NA COMPOSIÇÃO QUÍMICA DAS ÁGUAS Troca de bases As águas subterrâneas destes contextos cristalinos apresentam quase sempre um i.e.b. (índice de troca de bases) negativo, porém próximo de zero, isto é, -1 e +1 . Isso indica que os componentes das águas estão em equilíbrio com os terrenós nos quais circulam. Os valores fracamente negativos pertencentes às fontes São Benecdito, Nossa Senhora das Brotas, Nossa Senhora Aparecida e Jacob indicam aquisição predominante de alcalinos pelas águas.

Relações características Observando a Tabela $\mathrm{V}$, verifica-se que existe um grupo de águas onde a relação $\mathrm{rMg} / \mathrm{rCa}$ é menor que 1 , ou seja, a água apresenta mais cálcio do que magnésio. Essas águas podem ser classificadas como cálcicas. No outro grupo predomina o magnésio, sendo assim magnesianas, sem tomar em consideração o sódio e o potássio.

Classificação das águas Os valores da composição química das águas, em percentagens de miliequivalentes, foram plotados no diagrama de Piper.

A classificação das águas segundo esse diagrama mostrou os seguintes grupos:

a) bicarbonatadas cálcicas: São Sebastião, São Roque, São José;

b) bicarbonatadas magnesianaș: Santa Isabel, Filomena, Glória, Beleza, Boa Vista, São Francisco, Santa Bernadette;

c) bicarbonatadas sôdicas: Nossa Senhora do Rosário, Nossa Senhora Aparecida, São Bento;

d) cloretada sódica: Sônia;

e) bicarbonatadas mistas: Lindália, São Benedicto, São Bernardo, Nossa Senhora das Brotas, Santo Antonio, Bocaina, Jacob, Bom Jesus, Pompéia, Santa Tereza;

f) cloretada mista: São Jorge;

g) mista: da Saúde. 
Tabela V - Valores de índice de troca de bases e relaçôes características

\begin{tabular}{|c|c|c|c|}
\hline Local & Nome da Fonte & i.e.b. & $\mathrm{rMg} / \mathrm{rCa}$ \\
\hline Āguas de Lindóia & Lindália & $-1,28$ & 2,08 \\
\hline Águas de Lindóia & Santa Isabel & $-0,25$ & 4,00 \\
\hline Águas de Lindóia & São Sebastião & $+0,42$ & 0,65 \\
\hline Águas de Lindóia & Filomena & $+0,03$ & 4,54 \\
\hline Āguas de Lindóia & São Roque & $-0,33$ & 0,42 \\
\hline Āguas de Lindóia & Glória & $+0,07$ & 4,16 \\
\hline Águas de Lindóia & Beleza & $+0,03$ & 2,22 \\
\hline Itapira & Boa Vista & $-0,50$ & 1,66 \\
\hline Lindóia & São Benedicto & $-9,75$ & 0,38 \\
\hline Lindóia & São José & $-0,54$ & 0,35 \\
\hline Lindóia & São Francisco & $-0,18$ & 2,22 \\
\hline Lindóia & São Bernardo & $-1,35$ & 0,69 \\
\hline Lindóia & Sta. Bernadette & $-1,21$ & 3,57 \\
\hline Lindóia & Nossa Sra. das Brotas & $-4,42$ & 2,38 \\
\hline Lindóia & São Jorge & $-0,47$ & 2,77 \\
\hline Serra Negra & Nossa Sra. do Rosário & $-2,00$ & 5,55 \\
\hline Serra Negra & Santo Antonio & $-1,42$ & 0,94 \\
\hline Serra Negra & Nossa Sra. Aparecida & $-12,00$ & 2,17 \\
\hline Amparo & Bocaina & $-1,46$ & 0,48 \\
\hline Amparo & Jacob & $-2,21$ & 0,84 \\
\hline Monte Alegre do Sul & Bom Jesus & $-0,92$ & 0,52 \\
\hline Monte Alegre do Sul & da Saúde & $-0,06$ & 1,25 \\
\hline Socorro & São Bento & $-1,50$ & 0,69 \\
\hline Socorro & Pompéia & $-0,57$ & 0,79 \\
\hline Valinhos & Sônia & $-2,00$ & 1,11 \\
\hline Valinhos & Santa Tereza & $-1,85$ & 1,53 \\
\hline
\end{tabular}


Podemos separar as águas em 3 grupos não muito diferenciados. O grupo I abrangendo $76,9 \%$ das fontes, o grupo II, $7,6 \%$ e o grupo III, $15,3 \%$. No grupo I identifica-se um subgrupo cujo quadro geológico é predominantemente de rochas gnáissicas. No segundo subgrupo as rochas são graníticas e gnáissicas. Os grupos II e III refletem águas de litologias mais complexas.

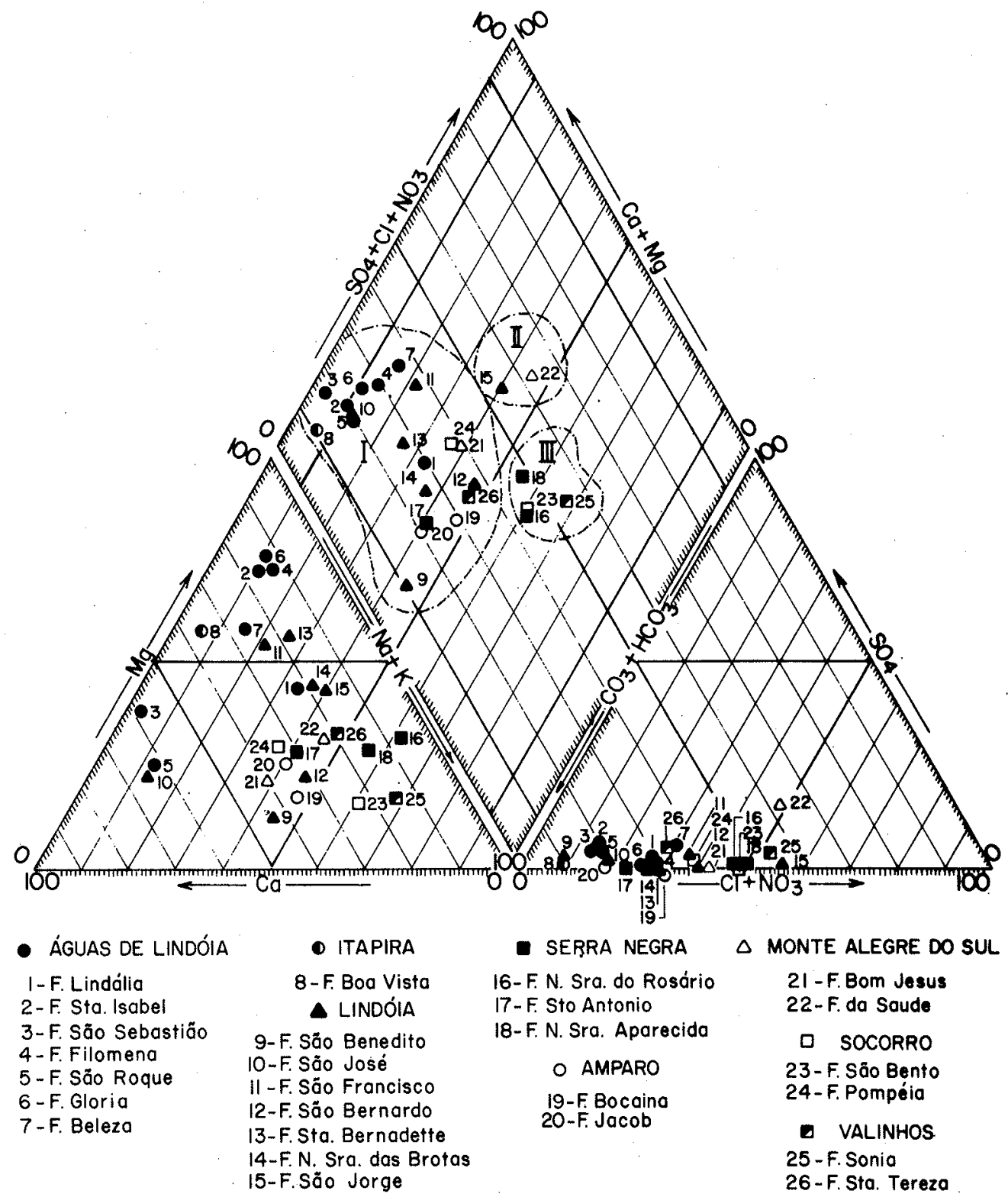

Figura 2 - Diagrama de análise de água segundo Piper 
CONCLUSÃo As águas estudadas separam-se em 2 grupos não muito distintos. Esta separação observa-se no $\mathrm{pH}$, sendo 5,3 a 5,7 para a região de Águas de Lindóia, Lindóia e Itapira e 4,7 para a região de Serra Negra, Amparo, Monte Alegre do Sul, Socorro e Valinhos.

As águas de Äguas de Lindóia, Lindóia e Itapira são bicarbonatadas cálcicas, bicarbonatadas magnesianas e cloretadas mistas. As de Serra Negra, Socorro, Valinhos, Amparo e Monte Alegre do Sul são bicarbonatadas mistas, bicarbonatadas sódicas e mistas.

Nos elementos traços, observa-se uma falta de iodeto e brometo nas águas das fontes de Águas de Lindóia e Lindóia, fluoreto mais ou menos igual, salvo nas de Nossa Senhora do Rosário. Em resumo, pode se concluir que não existe uma separação nítida de tipos de águas, no que se refere a composição química (sólidos totais dissolvidos, elementos maiores). Isso reflete a litologia não muito diferenciada, sendo esta na maioria composta de rochas de gnaisse Amparo com facies gnáissico e migmatítico com variações restritas.

As águas podem ser consideradas como minerais exclusivamente pelo critério de radioatividade nas fontes. Ainda podem ser classificadas como hipotermais as águas das fontes Filomena, São Roque, Glória e Beleza.

Agradecimentos Agradecemos ao Instituto de Geociências pelo apoio logístico e à Fundação ao amparo da Pesquisa do Estado de São Paulo (FAPESP) pela ajuda financeira.

Ainda os nossos agradecimentos para os administradores, gerentes e proprietários das fontes que nos receberam sempre com gentileza e facilitaram o nosso trabalho. Nossos agradecimentos especiais para o Sr. Agostinho Godoy, ex-prefeito de Lindóia, por sua valiosa ajuda.

Queremos expressar nossos agradecimentos também à química Maria Helena Oliveira (IEA), que gentilmente se prontificou para fazer as determinações de radioatividade das amostras fornecidas.

\section{BIBLIOGRAFIA}

CASTANY, G. - 1967 - Traité pratique des eaux souterraines - Dunod, Paris.

LONGO, O.W. - 1967 - Ȧguas radioativas no Estado de São Paulo. - Rev. do IGG n. 19.

PASSOS Guimarães, J.E. - 1946 - Fontes da Cidade de Lindóia -- Rev. do IGG Vol. IV., Ano IV, No 4.

SOUZA LOPES, R. - 1956 - Águas Minerais do Brasil - DNPM - Rio de Janeiro.

SZIKSZAY, M. \& TEISSEDRE, J.M. - 1977 - Análise hidrogeoquímica preliminar das fonte dos arredores da bacia de São Paulo. - Rev. Bras. de Geociências, 7(1):32-44.

WERNICK, E. - 1967 - A geologia da região de Amparo (Leste do Estado de São Paulo)

- Tese de doutoramento - FFCL de Rio Claro, Univ. de Campinas. 